\title{
Muscular Dystrophies at Different Ages: Metabolic and Endocrine Alterations
}

\section{Oriana del Rocío Cruz Guzmán, Ana Laura Chávez García, and Maricela Rodríguez-Cruz}

Laboratorio de Biología Molecular, Unidad de Investigación Médica en Nutrición, Hospital de Pediatría, Centro Médico Nacional Siglo XXI, IMSS, 06703 Ciudad México, DF, Mexico

Correspondence should be addressed to Maricela Rodríguez-Cruz, maricela.rodriguez.cruz@gmail.com

Received 21 December 2011; Accepted 2 April 2012

Academic Editor: Huan Cai

Copyright ( 2012 Oriana del Rocío Cruz Guzmán et al. This is an open access article distributed under the Creative Commons Attribution License, which permits unrestricted use, distribution, and reproduction in any medium, provided the original work is properly cited.

\begin{abstract}
Common metabolic and endocrine alterations exist across a wide range of muscular dystrophies. Skeletal muscle plays an important role in glucose metabolism and is a major participant in different signaling pathways. Therefore, its damage may lead to different metabolic disruptions. Two of the most important metabolic alterations in muscular dystrophies may be insulin resistance and obesity. However, only insulin resistance has been demonstrated in myotonic dystrophy. In addition, endocrine disturbances such as hypogonadism, low levels of testosterone, and growth hormone have been reported. This eventually will result in consequences such as growth failure and delayed puberty in the case of childhood dystrophies. Other consequences may be reduced male fertility, reduced spermatogenesis, and oligospermia, both in childhood as well as in adult muscular dystrophies. These facts all suggest that there is a need for better comprehension of metabolic and endocrine implications for muscular dystrophies with the purpose of developing improved clinical treatments and/or improvements in the quality of life of patients with dystrophy. Therefore, the aim of this paper is to describe the current knowledge about of metabolic and endocrine alterations in diverse types of dystrophinopathies, which will be divided into two groups: childhood and adult dystrophies which have different age of onset.
\end{abstract}

\section{Introduction}

There are about 30 different types of muscular dystrophies caused by alterations in diverse genes, which are characterized by the progressive loss of muscle in accordance with age of onset, severity, and the group of muscles affected [1]. The altered protein in most of these dystrophies is located in muscle fiber and is linked to other proteins, enzymes, or extracellular matrix [2]. Myopathologies are associated with different ages of onset, for example, Duchenne muscular dystrophy (DMD) and Becker muscular dystrophy (BMD) as well as Emery-Dreifuss muscular dystrophy (EDMD) demonstrating their first clinical manifestations during childhood [3], whereas some laminopathies such as myotonic dystrophy or limb-girdle muscular dystrophy are developed during adulthood [4]. This group of diseases can cause different physical symptoms such as contractures and scoliosis, respiratory impairment, swallowing and feeding difficulties, and, in some cases, metabolic alterations have been reported
$[4,5]$. Even so, the primordial clinical sign is muscle weakness $[4,5]$.

Skeletal muscle is responsible for $70-80 \%$ of whole body insulin-stimulated glucose uptake, disposal, and storage; therefore, this tissue is considered the major "player" in energy balance [6]. Furthermore, skeletal muscle has influence on the metabolism and storage of lipids and plays an important role in hormone signaling in insulin sensitivity [6]. Insulin receptors are localized in the cell membrane of target tissues (liver, adipose tissue, and muscle fibers) [7, 8]. It is important to emphasize that in dystrophinopathies the cell membrane of myocytes is damaged [3]. We have hypothesized that dysfunction of membrane of myocytes could alter the insulin receptor function, and as a result an increase may occur in the risk for developing insulin resistance. This fact will be discussed later. Insulin resistance is an important factor for the development of type II diabetes and a risk factor for cardiovascular disease, dyslipidemia, hypertension, and obesity $[6,9]$. The progression of muscular damage depends 
on protein mutation [3]. However, it is important to consider that muscle damage may be age related. The aim of this paper is to describe the current knowledge about of metabolic and endocrine alterations in diverse types of dystrophinopathies, which will be divided into two groups: childhood and adult dystrophies which have different age of onset.

\section{Childhood Dystrophies}

2.1. Clinical Characteristics of Duchenne/Becker Muscular Dystrophy. DMD has an incidence of 1/3500 live male births [10]. Initial symptoms begin in early infancy, presenting with muscular weakness between 2 and 4 years of age [11]. This appears when the patient begins to walk [12]. These hip weaknesses will be manifested in an awkward walk with a tendency to fall; later, stair climbing becomes difficult [12]. A classic sign of muscular weakness is Gower's sign, which indicates weakness of the pelvic girdle muscles $[11,12]$. Usually, joint contractures at the ankles and hips are increased as the disease progresses $[11,12]$. Finally, the development of muscle atrophy leads to wheelchair dependency, which typically occurs between 9 and 12 years of age [10]. The susceptibility for lung infections increases and respiratory capacity decreases [13]. Respiratory insufficiency appears at $\sim 14$ years of age and may result in death at $\sim 25-30$ years of age [13]. Another cause of death may be cardiomyopathy, which begins at $\sim 5$ years of age and evolves in a parallel manner with progression of the disease until this condition eventually leads to the patient's death [14]. Even so, cardiomyopathy is responsible for $\sim 60-80 \%$ of deaths [14].

Eagle et al. [15] reported a mean age of death of 14.4 years in the US during the decade of the 1960s, and this value increased to 25.3 years of age in 1990 . Fortunately, advances in the treatment of dystrophinopathies have improved life expectancy because patients may reach adulthood in the third and in some cases the fourth decade of life [15].

Becker muscular dystrophy (BMD) is clinically similar to DMD but is a less severe form of myopathy, affecting $1 / 30,000$ males [16]. Patients with BMD start to show clinical signs between 2 and 20 years of age. Compared to DMD, progression in BMD is slower $[17,18]$. Some BMD patients present clinical signs similar to those of DMD, whereas some patients are still able to walk at the age of 60 years [19]. Inability to walk prevails at about 30 years old, and death is frequently present 30 years after the appearance of the first clinical signs [20]. Cardiomyopathy usually occurs in $73 \%$ of BMD patients $>40$ years old [20].

Symptoms of Emery-Dreifuss muscular dystrophy (EDMD) generally appear during the first decade of life [21]. The principal clinical characteristics are contractures of the neck extensor muscle, spine, Achilles tendons, and elbows [22]. After muscle weakness, wasting appears during the end of the second decade of life and begins in a humeroperoneal distribution [23]. Cardiac complications begin at the end of the second decade, and sudden cardiac death due to ventricular dysrhythmia is common in this dystrophy [24].

DMD and BMD are X-linked diseases caused by mutations in the DMD gene, which is responsible for encoding dystrophin protein and is located at locus Xp21 [25-27].
Dystrophin protein is associated with an oligomeric protein complex known as dystrophin-glycoprotein complex or dystrophin-associated protein complex $[28,29]$. The mechanical function of the dystrophin-glycoprotein complex is to stabilize the plasma membrane (sarcolemma) during the stress of repeated contraction and relaxation cycles [30]. In patients with DMD, dystrophin is absent in the sarcolemma, whereas in BMD its expression is greatly reduced but is still located in the sarcolemma [31]. Mutations (deletions, duplications, point mutations) cause the lack or semilack of dystrophin [32]. These mutations have many functional and structural consequences in skeletal muscle, in DMD patients; muscle biopsy characteristically demonstrates necrotic or degenerating muscle fibers [32]. These necrotic fibers are surrounded by macrophages. Small immature centrally nucleated fibers are also observed, reflecting muscle regeneration from myoblasts [31-33] that results in a balance between necrotic and regenerative processes in the early phase of the disease. Later, the regenerative capacity of the muscles appears to be exhausted, and muscle fibers are gradually replaced by connective and adipose tissue (Figure 1) [33].

EDMD is usually inherited as an X-linked recessive disorder, although an autosomal dominant form has also been described [34]. This dystrophy is caused by mutations in the gene for emerin (EMD gene) localized on chromosome $\mathrm{Xq} 28$ [35]. Emerin is an integral serine-rich protein of the nuclear envelope inner membrane, which is ubiquitously expressed in most tissues and contains 254 amino acids [36]. The autosomal form of EDMD is caused by mutations in the LMNA gene localized at chromosome 1q21.2-q21.3, which encodes an A-type nuclear lamin [37]. This lamin is an intermediate filament protein associated with the inner nuclear membrane [38]. Emerin interacts with both lamin A and lamin $\mathrm{C}$ in the nucleus. It has been proposed that these mutations may result in increased nuclear fragility during mechanical stress or increased susceptibility to apoptosis [39].

2.2. Endocrine System. The most important endocrine alteration in DMD/BMD patients is hypogonadism, which has been related to dystrophies [40]. Consequences of this state are delayed puberty, growth failure, osteoporosis, and metabolic abnormalities [40-42]. In 2008, Al-Harbi et al. [40] measured total and free serum testosterone levels in 59 men with different dystrophinopathies. Results obtained showed that 54\% had low total testosterone, 39\% had low total and free values, and $8 \%$ had low free with normal total levels [40]. In addition to Becker and Duchenne dystrophies $(n=$ 12 ), other dystrophinopathies were included such as monotonic dystrophy $(n=12)$, facioscapulohumeral dystrophy $(n=11)$, metabolic myopathy $(n=7)$, and body myositis ( $n=17$ ) [40]. Interestingly, there were no significant differences in the prevalence of hypogonadism among the various forms of myopathy, even after considering age as a confounder [40]. It has been established that testosterone levels decline with aging, and this is associated with decreased muscle mass and strength in healthy subjects [43]. Testosterone treatment increases muscle mass and strength in older 


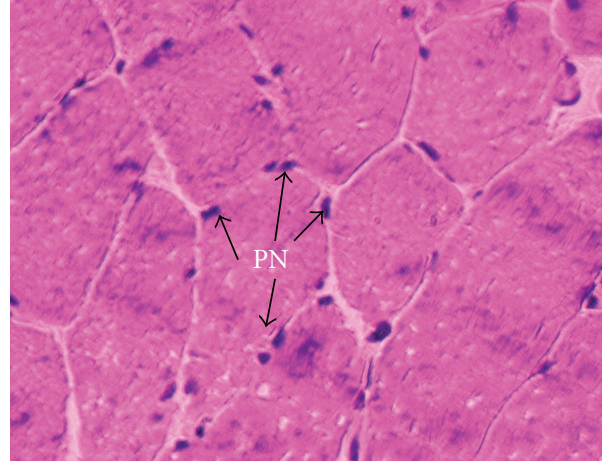

(a)

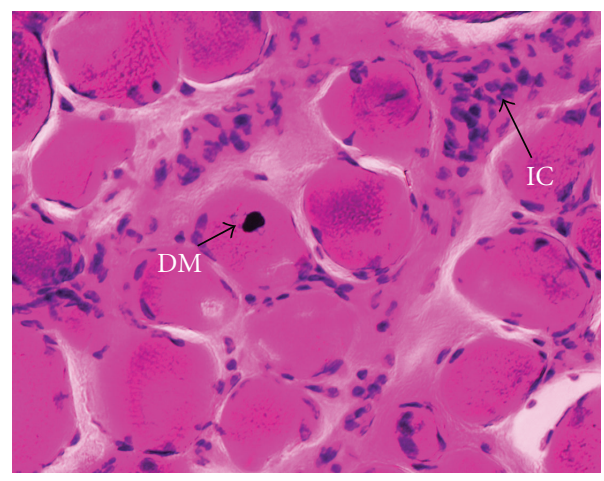

(b)

FIGURE 1: Histology of necrotic skeletal muscle. Image (a) showed a normal skeletal muscle from quadriceps muscle, characterized by healthy myofibres with peripheral nuclei (PN). Skeletal muscle of control subjects was obtained from males without dystrophinopathies at 40 years old. Image (b) showed a necrotic skeletal muscle from quadriceps muscle of a patient with DMD/DMB at five years old, characterized by infiltrating inflammatory cells (ICs) and degenerating myofibres (DMs). Transverse muscle sections stained with haematoxylin and eosin. Scale bar represents $50 \mathrm{~m}$. This biopsy was obtained for the purpose of performing diagnostic.

hypogonadal males [44]. The importance of testosterone in the maintenance of muscle mass is critical, and testosterone therapy should be considered when hypogonadism is present $[43,44]$.

Growth hormone (hGH) has anabolic effects in normal skeletal muscle [45]. It has been suggested in only one study that this hormone plays a role in the pathogenesis of DMD, but there is insufficient evidence to support that idea [45, 46].For instance, in one study, treatment with hGH was administered to DMD patients, but no effect was shown on clinical status and natural history of DMD, either beneficial or detrimental [47]. In addition, Merlini et al. [45] demonstrated in DMD patients with impaired hGH secretion that no association exists between diminished secretion of hGH and different forms of the disease. Interestingly, there is a case report of hGH treatment of a young male with DMD with hGH deficiency who showed improved growth velocity and motor function [45]. Controversies still exist about the benefit and the role of hGH and the resolution in regard to treatment administration with hGH for counteracting short stature. This treatment should be individualized with the objective to obtain improved results [40].

No effective treatment has yet been demonstrated to ameliorate the various consequences of muscular dystrophies [48]. However, in recent years a range of approaches have been developed to correct the genetic defect, restore functional expression of dystrophin, slow disease progression, and improve the quality of life for DMD patients [49]. Those treatments can be categorized into three classes: genetic, cellbased, and pharmacological approaches such as corticosteroids [50].

The use of pharmacological treatment with corticosteroids is justified by the fact that DMD is characterized by aggressive inflammation, and there is strong evidence that this contributes to myofiber necrosis $[48,51]$. Until a cure for $\mathrm{DMD}$ is found, treatment will involve administration of corticosteroids combined with interventions to alleviate cardiac and respiratory problems [51].

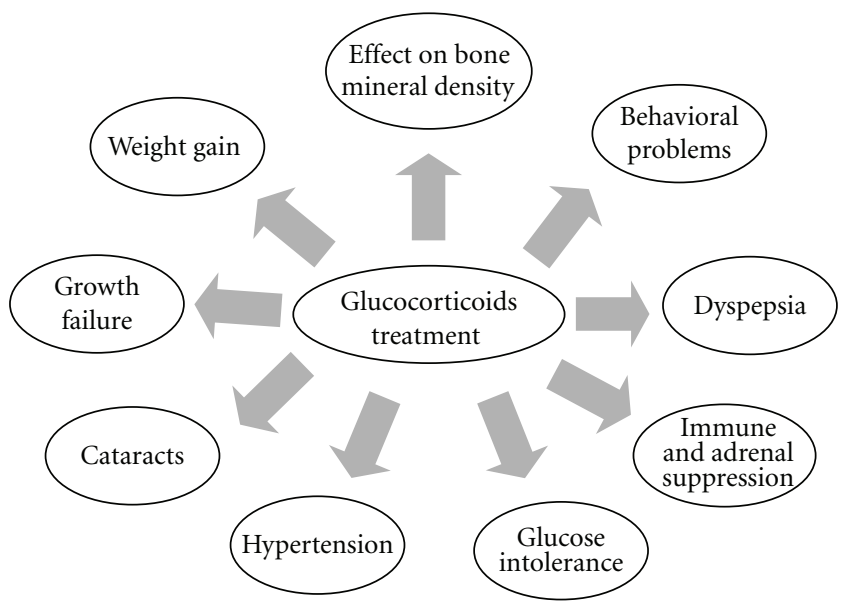

FIGURE 2: Side effects of glucocorticoid treatment in muscular dystrophies.

However, it is important to note that corticosteroids have a catabolic effect on muscle (nonexercised muscle) and have an effect on preserving existing muscle fibers and reducing inflammation, even though their exact mechanism of action in dystrophic skeletal muscle is unknown $[12,48]$. Moreover, use of glucocorticoids [GC] in patients with DMD and BMD is common, but GCs have different side effects (Figure 2) [48]. Two of the most important side effects are growth failure and delayed puberty [52]. Currently, there are no studies examining the outcomes of treating delayed puberty in patients with DMD.

2.3. Metabolic Alterations. About a decade ago, clinical researchers began to notice that patients with DMD tended to present obesity [53]. However, it was necessary to demonstrate the prevalence of obesity in children with DMD because obesity had only been described from clinical experience [54]. For this reason, it was also necessary to measure 
body composition of these patients which, in turn, depended on technology available [55].

With the advance in knowledge, it was observed that DMD patients also develop malnutrition as a consequence of the progression of the illness [56]. In the following paragraphs, some metabolic issues will be described such as malnutrition and obesity and, additionally, some abnormalities in glucose metabolic pathway.

2.3.1. Malnutrition. In patients with dystrophinopathies, nutrition is a problem to consider. It has been reported that $50 \%$ of DMD patients are underweight by the age of 18 [54]. Some studies have shown that this problem generally is caused by feeding difficulties, gastrointestinal dysfunction, and reduced weight gain [57]. It has also been observed that chewing and swallowing difficulties in both ambulant and nonambulant DMD patients are related to increased weakness of masticatory muscles, malocclusion, and other abnormalities of the oropharyngeal process [58]. Additionally, gastric distension has been reported in DMD and BMD, which can contribute to delay gastric emptying, gastroesophageal reflux, and subsequent nutritional disturbances [59].

Malnutrition has also been observed in patients with $\mathrm{DMD} / \mathrm{BMD}$ who are severely compromised by respiratory failure [13]. This fact has been described in advanced stages of those dystrophinopathies when breathing effort increases and, as a consequence, caloric requirements drastically increase. Gonzalez-Bermejo et al. [13] showed that specific nutritional measures should be taken when patients have advanced forms of dystrophy, and mechanical ventilation becomes necessary because, surprisingly, these patients have balanced energy intakes and resting energy expenditure (REE); hence, they are not likely to suffer from significant malnutrition. However, Gonzalez-Bermejo et al. [13] found that $34 \%$ of patients aged $25 \pm 4$ years who had received nocturnal mechanical ventilation had a decrease of REE. This effect was also observed in patients with DMD of different age groups (10-11 years; $12-14$ years; $15-17$ years; $18-29$ years), where REE was significantly lower than the value obtained for healthy controls [13]. Both the low REE and the low physical activity during the early teenage years result in a low energy requirement and may be related to obesity that frequently occurs in this age group [13]. In contrast, in later stages of the disease, patients increase their basal physical activity [60]. It is possibly due to the presence of respiratory failure, may lead to a high energy requirement, and thus becomes one of the risk factors for development of malnutrition [60]. Additionally, it is important to consider that loss of the ability to self-feed in $\mathrm{DMD} / \mathrm{BMD}$ patients is very common [61]. The length of meal time also increases with age, ranging from a mean of $18 \mathrm{~min}$ in younger patients to a mean of $32 \mathrm{~min}$ in older patients [62]. The increase in time is probably related to a combination of increasing weakness of the masticatory muscles and difficulties in chewing and swallowing [62]. Perhaps it would be a good choice to introduce dietary modifications as cutting food into smaller pieces and changing the texture to soft foods in order to facilitate chewing and to reduce meal time [62].
2.3.2. Obesity. As previously mentioned, obesity is an important identified problem in patients with dystrophinopathies [53]. Body mass index (BMI) is the most frequently used indicator in clinical practice in order to make the diagnosis of overweight or obesity [63]. Nonetheless, the main limitation of the BMI is that it does not discriminate between fat mass and lean mass [64]. It has been observed that individuals with a BMI within normal limits have fat mass measurements that fall within values considered as obesity when these have been measured with more precise methods [64]. Therefore, it is necessary to measure fat mass through body composition. It is possible to evaluate the general nutritional status by body weight composition, which could be estimated by measures such as skinfold thickness (ST), dual energy X-ray absorptiometry (DXA), bioelectrical impedance analysis (BIA), and magnetic resonance imaging (MRI) [65].

At the age of 7 years, obesity may occur in patients with DMD, and by the age of 13 years prevalence is $54 \%$, and distribution of body fat is centralized [54]. Moreover, Martigne et al. [56] provided additional information about nutritional status in DMD patients during different ages. This group of investigators studied the progression of nutritional status in 17 DMD patients born prior to 1992 . Obesity was evaluated using Griffiths \& Edwards charts. According to it, obesity was defined by body weight/age ratio $\geq 151 \%$. At the age of 13 years, those patients showed a prevalence of $73 \%$ for obesity and $4 \%$ for underweight. At age 15-26 years, the prevalence of obesity decreased to $47 \%$ and prevalence of underweight increased to $34 \%$. Also, obesity at the age of 13 years was associated with later obesity, whereas normal weight status and underweight in 13-year-old patients were predicted later [56].

It has been observed that obesity contributes to the progression of the disease by exerting extra force on already weakened muscle groups, essentially decreasing mobility [56]. Obesity also has implications on increased respiratory involvement as well as poorer psychosocial development [57]. There is one hypothesis that describes the positive association of loss of ambulation and obesity increment in DMD patients [12, 13]. Although Martigne et al. [56] found no relation between the age of ambulation loss and development of obesity.

Generally, fat mass is higher in patients with dystrophy than in healthy subjects [66]. Indeed, as the dystrophic process advances with age, percentage of fat mass increases at least during the first two decades of life [67]. In fact, body composition of DMD patients has been evaluated (by bioelectrical impedance analysis and skinfold-thickness measurement), and the results show that lean mass in DMD $(65.3 \%)$ was lower (between $\sim 12 \%$ and $25 \%$ ) than in healthy children, whereas fat mass in DMD (31.9\% versus $22 \%)$ was higher than in control children [67]. Additionally, a positive correlation was found between age and percentage of fat mass and a negative correlation between age and percentage of lean mass [67]. The authors suggest that muscle may have been replaced by connective tissue [67]. In this context, Zanardi et al. [55] studied obese and nonobese children with DMD and evaluated the alteration of body composition in boys with DMD using magnetic resonance imaging. Only obese 
children showed a markedly increased fat mass (>50\%), whereas nonobese children with DMD showed fat mass values similar to healthy boys [55]. In both obese and nonobese children with DMD, the characteristic that was dramatically reduced was muscle mass, showing a reduction of $27 \%$ of muscle volume compared with control subjects [55].

It is important to emphasize that the advance in the knowledge and development of new technologies for assessing nutritional status has shown that patients with DMD present abnormal nutritional status such as obesity or malnutrition as part of the natural course of DMD. These alterations are related to advancing age because dystrophy progresses over the course of time.

2.3.3. Glucose and Insulin Metabolism. To date, relatively little is known about metabolic alterations in patients with DMD and BMD. However, there are studies that described some disturbances in glucose metabolism, which include reduced glycolytic substrates, reduced activity of glycolytic enzymes, and defects in insulin receptor signal transduction (Figure 3) [68].

Some studies have suggested that there are metabolic differences in the skeletal muscle of patients with DMD and healthy subjects [69]. For example, it has been proven that the concentration of glycolytic substrate glucose, gluconeogenic amino acids such as glutamine and alanine and lactate, a glycolytic product, is lower in DMD patients as compared to controls in skeletal muscle [70]. Also, the decrease in the concentration of lactate in the muscle of DMD patients may be due to the reduction in anaerobic glycolytic activity or lower substrate concentration [71]. As a result, the low concentration of glucose metabolism substrates may be one of the reasons for energy deficit in DMD patients [72].

Nishio et al. also showed that glucose serum concentration in DMD patients is significantly lower and is associated with low creatine kinase activity. This fact may probably be one of the causes of energy deficit in DMD patients [72]. These findings also have a relationship with other causes described in different studies in which glycolytic enzymes were found to have reduced activity in lactate dehydrogenase, aldolase, and pyruvate kinase from muscle biopsies of DMD patients, supporting reduced anaerobic glycolytic activity [68]. Those results are in agreement with the low concentration of previously described glucose metabolism substrates.

Although there are no reports describing whether DMD patients present insulin receptor signal transduction alterations, some studies have evaluated whether there is a defect in insulin secretion or receptor [73]. These studies hypothesized that the possible changes in the sarcolemma of skeletal muscle cells could produce defects in insulin signaling [73]. This has been proposed because patients with diabetes present skeletal muscle weakness that could lead to changes in the sarcolemma as a result of defects in insulin receptor internalization and processing that have been well described in insulin resistance and diabetes [74]. Further research is needed to clarify this hypothesis.

There are other types of evidence that have demonstrated damage of the plasma membrane of myocytes of boys with

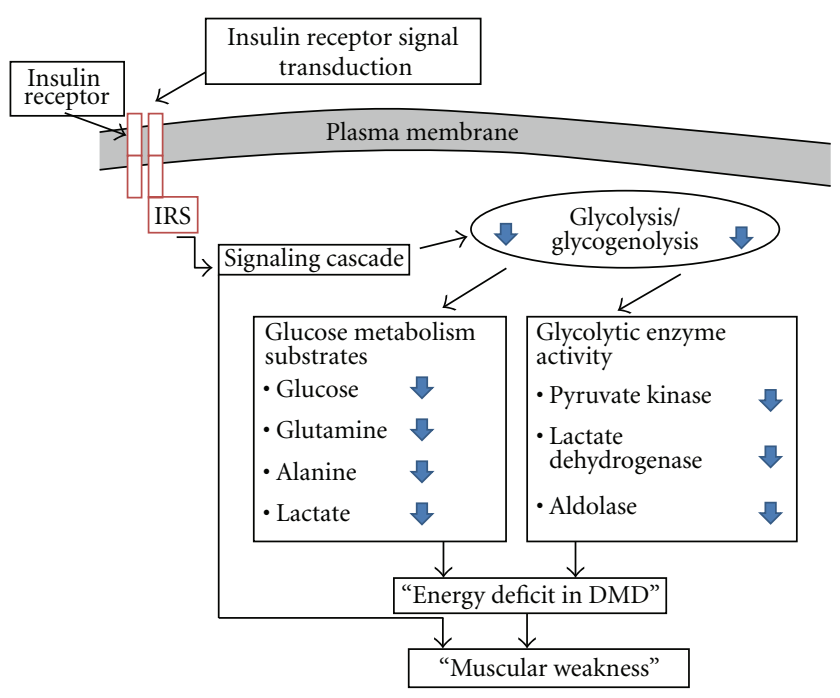

FIGURE 3: Some aspects of impaired glucose metabolism in patients with childhood muscular dystrophies. The damage in the glucose metabolism, no matter the reason, may probably be one of the causes for energy deficit in DMD patients, and this low energy could result in muscular weakness in muscular dystrophies.

DMD and BMD [75]. It is well known that membrane properties depend on phospholipid composition [76]. A significant reduction has been observed in muscle biopsies of DMD patients in some membrane components or phospholipids such as total creatine, glycerophosphorylcholine, phosphoryl choline, carnitine, choline, and acetate [68], and lower levels of choline-containing compounds indicate membrane abnormalities. Additionally, a lower ratio of trimethyl amides (TMAs) compared with healthy tissue has been demonstrated in biopsies of DMD patients. TMAs are constituents of phospholipid metabolism and cell membranes, and decreased TMA is considered to be associated with a lower number of cells and reduced rate of membrane synthesis [77]. Decrease in TMA may reflect degenerative changes in the muscles of patients with DMD, resulting in alterations in signal transduction that take place in the sarcolemma [77].

However, despite the above-mentioned evidence, scarce information exists about the alterations in glucose and insulin metabolism in DMD patients. There is only one study by Freidenberg and Olefsky in which an oral glucose tolerance test and the measurement of insulin binding on erythrocytes were performed in DMD patients and agematched healthy males. The results of this study showed that insulin binding in erythrocytes was $20-30 \%$ lower in DMD patients than in healthy subjects. This difference indicated a lower affinity of insulin to its receptor in erythrocytes in DMD patients. This alteration may be present prior to the development of insulin resistance, which may occur in severely immobilized patients. One possible cause for this fact is the increased progression of the dystrophy. Furthermore, in the same study, it was found that patients with DMD had elevated levels of glucose and insulin in comparison to a healthy control group [73]. 
TABLE 1: Clinical aspects, metabolic and endocrine issues on muscular dystrophies.

\begin{tabular}{|c|c|c|c|c|c|c|c|}
\hline & & Age of onset & $\begin{array}{c}\text { Clinical } \\
\text { characteristics }\end{array}$ & Metabolic issues & Endocrine issues & Clinical complications & Life span \\
\hline \multirow{2}{*}{$\begin{array}{l}\text { Childhood } \\
\text { Muscular } \\
\text { Dystrophy }\end{array}$} & $D M D$ & Early infancy & $\begin{array}{l}\text { Muscle weakness } \\
\text { Gower's sign Joint } \\
\text { contractures } \\
\text { Muscle atrophy }\end{array}$ & $\begin{array}{l}\text { Obesity } \\
\text { Insulin resistance } \\
\text { Malnutrition }\end{array}$ & $\begin{array}{l}\text { Hypogonadism } \\
\text { Delayed puberty } \\
\text { Low testosterone } \\
\text { level Growth failure }\end{array}$ & $\begin{array}{l}\text { Wheelchair dependency } \\
\text { Loss of ability of } \\
\text { self-feeding Gastric } \\
\text { distension Respiratory } \\
\text { insufficiency } \\
\text { Cardiomyopathy }\end{array}$ & $\begin{array}{c}25-30 \\
\text { years old }\end{array}$ \\
\hline & $B M D$ & $2-20$ years old & & & & & $\begin{array}{l}\text { Variable: } \\
4 \text { th or } 5 \text { th } \\
\text { decade of } \\
\text { life } \\
\end{array}$ \\
\hline \multirow[t]{2}{*}{$\begin{array}{l}\text { Adult } \\
\text { Muscular } \\
\text { Dystrophy }\end{array}$} & MD1 & $\begin{array}{c}\text { 20-60 years } \\
\text { old }\end{array}$ & $\begin{array}{l}\text { Myotonia Muscle } \\
\text { weakness }\end{array}$ & $\begin{array}{l}\text { Obesity Insulin } \\
\text { resistance } \\
\text { Hyperinsulinemia } \\
\text { Hypertriglyc- } \\
\text { eridemia Glucose } \\
\text { intolerance }\end{array}$ & $\begin{array}{l}\text { Hypogonadism } \\
\text { Oligospermia Low } \\
\text { testosterone levels } \\
\text { Reduced fertility } \\
\text { Erectile dysfunction } \\
\text { Testicular atrophy }\end{array}$ & $\begin{array}{l}\text { Hypogammaglobulinemia } \\
\text { Pneumonia Cardiac } \\
\text { arrhythmias }\end{array}$ & $\begin{array}{l}\text { Variable: } \\
\text { 5th or 6th } \\
\text { decade of } \\
\text { life }\end{array}$ \\
\hline & MD2 & $\sim 48$ years old & & & & & \\
\hline
\end{tabular}

In summary, in muscular dystrophies which have childhood age of onset, such as DMD and BMD, there are common and well known clinical characteristics and complications that lead the patient to death (Table 1). But also some common metabolic and endocrine alterations have been identified in both DMD and BMD. One of the most important metabolic aspects is nutritional status. Obesity and malnutrition have been identified in these dystrophinopathies. Furthermore, there are some biochemical aspects that have demonstrated an impaired glucose and insulin metabolism. Moreover, these patients present hypogonadism, which is important to emphasize that hypogonadism consequences are related to the age of onset. For instance, since hypogonadism is present in early infancy, these patients are going to present delayed puberty and growth failure (Table 1). However, since DMD/DMB patients have short life expectancy, secondary consequences of hypogonadism such as reduced fertility and oligospermia are less relevant.

\section{Adult Muscular Dystrophies}

Clinical features in muscular dystrophies also can appear in juvenile or adult age, and these phenotypes differ depending on mutation type [78]. Some muscular dystrophies in juvenile or adult age include distal myopathy, Miyoshi and Nonaka [79], inclusion body myositis (IBM) [80], facioscapulohumeral muscular dystrophy (FSHMD) [81], oculopharyngeal muscular dystrophy (OPMD) [82], distal myopathy [83], myotonic dystrophy (MD, type 1 or type 2) [84], and limb-girdle muscular dystrophy (LGMD 1B) [79]. However, we focused this paper on two last dystrophies.

3.1. Clinical Characteristics of Myotonic Dystrophy and $L G M D$. Myotonic dystrophy (MD) is the most common inherited neuromuscular disease in adults, with a global incidence of 1/8000 individuals [85]. Two types of MD exist: type 1 (MD1) and type 2 (MD2) $[85,86]$. MD1 is a chronic, slowly progressive, highly variable inherited multisystemic disease. MD1 results from an unstable (CTG) expansion in $3^{\prime}$ UTR of the MD protein kinase gene (MDPK) at $19 \mathrm{q} 13.3$ locus [84]. MD2 is caused by an unstable expansion of a CCTG tetraplet repeat in intron 1 of the ZFN9 gene localized on chromosome 3q21.3 [84]. The phenotypes of MD1 and MD2 have a broad spectrum of clinical signs that include mainly myotonia and muscle weakness. The first neuromuscular symptoms appear during a wide age range (20-60 years) [86]. Other clinical signs of these dystrophies include cataracts prior to 50 years of age, cardiac conduction defects, endocrine changes, testicular atrophy, insulin resistance, and hypogammaglobulinemia [84]. In MD2, clinical features appear in adulthood (median age 48 years) in contrast to adult-onset MD1 and childhood onset [87]. The majority of patients $(63 \%)$ die between 50 and 65 years of age [86, 87]. Pneumonia and cardiac arrhythmias are the most frequent primary causes of death, each occurring in 30\% of patients, which was much higher than expected for the general population [88].

Other types of dystrophy are LGMD, which describes a heterogeneous group of muscle disorders characterized by a predominant proximal distribution of limb-girdle, shoulder, and hip weakness [79]. At least 15 different genetic forms of LGMD are now known [79]. The phenotypes begin during early childhood to late adulthood [89]. The LGMD group is still growing today and consists of 19 autosomal dominant and recessive forms (LGMD1A to LGMD1G and LGMD2A to LGMD2M) $[84,89]$. The proteins involved are diverse and include sarcomeric, sarcolemmal, and enzymatic proteins [90].

3.2. Endocrine Alterations. Endocrine abnormities have been reported in MD2 and MD1 patients (Figure 4), including the alteration in testicular function such as hypogonadism 


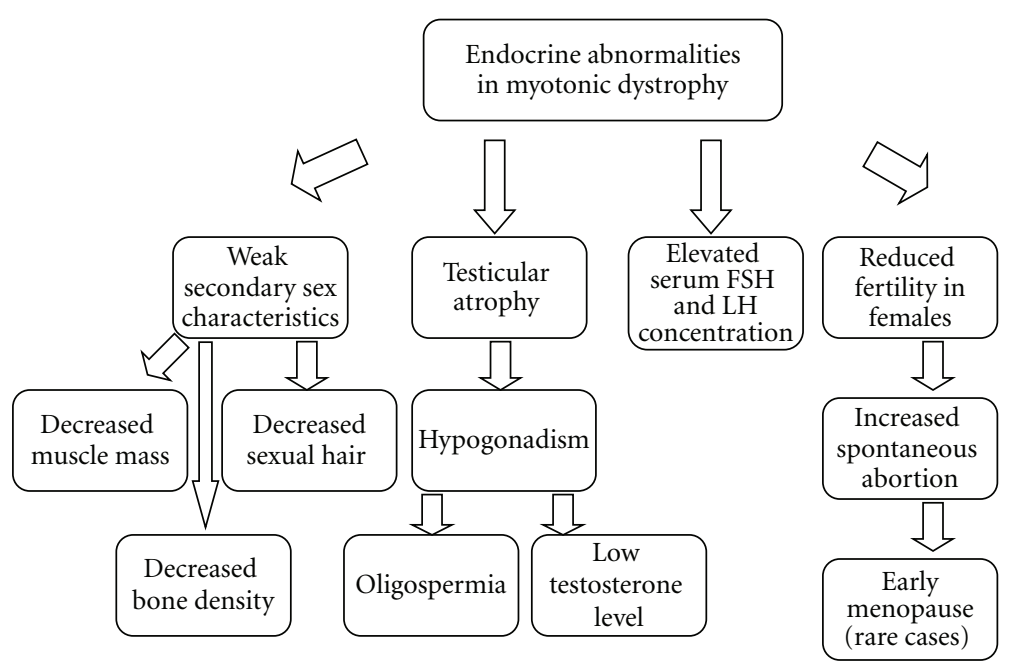

FIgURE 4: Endocrine abnormalities described in MD1/MD2.

leading to oligospermia [91], low levels of testosterone (T), and reduced spermatogenesis [92], resulting in reduced male fertility. In fact, hypogonadism may be a cause for erectile dysfunction (ED), which has been demonstrated in $25 \%$ of patients with MD1 [93]. The occurrence of ED is independent of the patient's age but may be related to other intrinsic factors of MD1 such as disease duration and severity and CTG expansion $[94,95]$. Also, those patients present elevated levels of follicle-stimulating hormone (FSH) and reduced $\mathrm{T}$ level in comparison to control subjects $[92,93,96]$.

Hypogonadism is very common in males with myopathies and involves both interstitial (androgenic) and tubular (spermatogenic) gonadal functions. In primary hypogonadism, luteinizing hormone $(\mathrm{LH})$ increases and $\mathrm{T}$ level is reduced $[93,94]$. In contrast, in compensated hypogonadism, LH increases and T levels are normal [93].

Testicular atrophy is reported to be the most prominent feature in $\sim 80 \%$ of MD1 patients $[97,98]$. Testicles of MD1 patients are characterized by an increase in the number and size of Leydig cells as well as tubular atrophy, hyalinization, fibrosis of the seminiferous tubules and reduced spermatogenesis. It has been reported that $46 \%$ of MD1 patients show hormonal evidence of interstitial gonadal failure [97, 99].

\subsection{Metabolic Alterations}

3.3.1. Malnutrition. Although MD patients demonstrate disorders of the oropharyngeal cavity, myotonia of the tongue and pharynx, impaired pharyngeal contraction, and slowing of esophageal peristalsis, to date, there have been no reports regarding the malnutrition state related to $\mathrm{MD}$ [4]. Loss of ability to cut and manipulate food leads to a loss of the ability of a person with MD to ensure adequate nutrition [100]. In this context it has been reported that $62 \%$ of patients with MD1 do not meet their daily energy requirements according to government recommendations: $55 \%$ of MD1 patients had a fat intake higher than the acceptable macronutrient distribution ranges [4]. Furthermore, 10\% of the MD1 group of patients were categorized as obese (BMI > 30) and 13\% had BMI values $<18.5$, which is in the underweight category [4]. Patients with MD1 have macronutrient and energy intake deficiencies as well as an insufficient intake of minerals (copper, zinc, and calcium) [57]. However, there are no reports regarding malnutrition in MD patients.

3.3.2. Obesity. In muscular dystrophy, plasma membrane is damaged, generating myofibers passing through cycles of deterioration and regeneration until the end of its repair capacity $[25,28-30]$. This induces the muscle fibers to be susceptible to the development of necrosis and to be replaced by fibrous connective tissue and adipose tissue [30]. Fibrotic tissue is still considered as lean tissue, so the increase in fat mass may be considered as a reflection of fat involution in muscles [30-32]. Myotonic dystrophy is linked to metabolic syndrome including insulin resistance, increased fat mass, and hypertriglyceridemia [58].

Progressive muscle loss associated with fat infiltration will carry a decrease in motor function and an increase in whole body fat mass index and regional fat-free mass index $[55,56]$. Therefore, there is a progressive worsening of disease leading to a decrease of the vital capacity as well as total lung capacity and increases in fat mass [56]. MD1 patients present lower regional (legs, arms, and trunk), fat-free mass index (FFMI), and higher fat mass index (FMI) than healthy individuals [101]. In MD1 patients, a correlation has been reported with an increased total fat-free mass index and decreased motor function and with both decreasing vital capacity and total lung capacity $[101,102]$.

Aitkens et al. [103] observed that patients with neuromuscular disease showed more cases of obesity and were more sedentary than control subjects (37\% versus 34\%). However, in this study only 11 patients with neuromuscular disease were analyzed, and only four of the patients had myotonic dystrophy [103]. Therefore, this is not the best reference to determine the prevalence of obesity in MD patients [54]. Recently, Kaminsky et al. [102] studied 106 patients 
with MD1 (46 males and 58 females) within a range of 55 years of age. These authors reported that the prevalence of obesity was $25.6 \%$ and hypertriglyceridemia was $47.6 \%$ [102]. The increased fat mass in MD1 patients could be considered a reflection of fat involution in muscles and a link with the metabolic disturbances in these patients [102].

3.3.3. Glucose and Insulin Metabolism. Patients with myotonic dystrophy have alterations in glucose metabolism, and it has been reported that these individuals have insulin resistance as an early manifestation [101]. Insulin resistance is the main cause of glucose intolerance in MD1 and, as a consequence, hyperinsulinemia may coexist such as a compensatory mechanism and may later lead to the onset of diabetes mellitus [101, 103].

However, the prevalence of diabetes mellitus in MD1 patients has not been proven. Muscle wasting and the low physical activity can make worse insulin resistance and lead to deregulation of protein catabolism [104].

Some hypotheses have been described to explain molecular insulin resistance in MD patients. One hypothesis is in regard to insulin receptor and the two existing isoforms: isoform A (IR-A), which lacks exon 11, and isoform B (IR-B), which includes exon 11 [105]. The insulin receptor B (IR-B) predominates in insulin-responsive tissues such as skeletal muscle. Interestingly, patients with MD1/MD2 express predominant insulin receptor isoform type A (IR-A) in skeletal muscle [106]. With a histological evaluation of MD muscle biopsies, it has been shown that the splicing changes in IR precede histological abnormalities [105]. The results showed that alterations in splicing occur prior to development of dystrophic changes, and this abnormal splicing may be a result of altered RNA binding due to the CUG expansion in the DMPK gene $[101,106]$.

Another metabolic alteration associated with glucose is abnormal insulin secretion in MD patients with normal insulin sensitivity [101]. This suggests damage to the $\beta$-cell secretory profile. This damage was represented by increased plasma proinsulin concentrations and a remarkably higherthan-normal early secretory response after oral glucose tolerance test in MD1 patients [107, 108]. A possible reason for this abnormal insulin secretion may be related with the protein kinase and the CUG expansion in the DMPK gene [108]. Protein kinase is involved in the modulation of the $\mathrm{Ca}^{+2}$ homeostasis in skeletal muscle cells, and $\mathrm{Ca}^{+2}$ homeostasis is crucial for $\beta$-cell secretion events [109]. If the alteration of calcium metabolism of the skeletal muscle also affects the $\beta$-cell, then the abnormal pattern of insulin secretion may be related to a malfunction of the MD1 protein kinase [109].

In summary, it has been reported that MD patients present obesity with a prevalence of $25.6 \%$ and that it is related to muscle atrophy. Obesity may be related to insulin resistance and metabolic disturbances. However, obesity does not explain damage in glucose metabolism because in myotonic individuals this metabolic alteration has been related to CUG expansion in the DMPK gene, which causes splicing changes in IR. This metabolic alteration has also been related to problems with insulin secretion. Therefore, all types of damage in glucose metabolism in MD patients are related to the problem in the gene itself and not with the problems caused by the pathology. In this context, in DMD it has been noted that the metabolic problems are as a result of the pathology, for example, damage in membrane permeability, problems with glycolytic enzymes, lower glucose metabolism substrates, and changes in the sarcolemma.

On the other hand, it is important to denote that in adult muscular dystrophies such as MD, metabolic abnormalities are similar to those identified in childhood muscular dystrophies (Table 1). Additionally, in MD1 and MD2 some endocrine alterations have been identified (Table 1). One of these alterations is hypogonadism, which has also been identified in childhood muscular dystrophies (DMD/BMD). In this case, since onset is during adulthood, the primary and more relevant consequences of hypogonadism are related to reduced fertility, reduced spermatogenesis, low testosterone levels, and erectile disfunction. In contrast to DMD/BMD, these patients had a normal growth and puberty.

\section{Conclusions}

Clinical and genetic characteristics of muscular dystrophies are diverse but all have one common characteristic: muscular atrophy. The muscle is one of the main tissues that regulates lipid and glucose metabolism by hormones such as insulin. It is important to consider that muscular dystrophies are related to weakness, fatigue, decreased mobility, and reduced physical working capacity. In addition to the muscular atrophy in these pathologies, replacement of skeletal muscle for fat and fibrotic tissue produces a reduction of the muscular mass; therefore, there is an imbalance for all these tissue functions. The combination of increased adiposity and sedentary lifestyle increases the risk for the development of metabolic syndrome. Age is an important factor in the muscular dystrophies, which produces the differences in clinical manifestation because age causes a more rapid progression of clinical, metabolic, and hormonal problems. For example, DMD patients often have short stature, whereas MD patients do not have height-related issues. DMD/BMD patients are frequently wheelchair-bound, and MD individuals do not present this limitation. DMD patients have problems with delayed puberty, whereas MD patients may have reproductive capabilities and have a functional sexual life. Metabolic problems may also increase if clinical manifestations begin in early age as in DMD and BMD. In this type of dystrophy, obesity is observed in the first decade, and during the course of time these patients may show malnutrition, whereas MD patients only develop obesity. Knowledge in regard to metabolic, physiological, and molecular alterations in muscular dystrophies will provide tools that will improve the quality of life for these patients.

\section{Abbreviations}

DMD: Duchenne muscular dystrophy

BMD: Becker muscular dystrophy

EDMD: Emery-Dreifuss muscular dystrophy

DYS: Dystrophin C-terminus 


$\begin{array}{ll}\text { hGH: } & \text { Growth hormone } \\ \text { GC: } & \text { Glucocorticoids } \\ \text { REE: } & \text { Resting energy expenditure } \\ \text { BMI: } & \text { Body mass index } \\ \text { ST: } & \text { Skinfold thickness } \\ \text { DXA: } & \text { Dual energy X-ray absorptiometry } \\ \text { BIA: } & \text { Bioelectrical impedance analysis } \\ \text { MRI: } & \text { Magnetic resonance imaging } \\ \text { TMA: } & \text { Trimethyl amides } \\ \text { IBM: } & \text { Inclusion body myositis } \\ \text { FSHMD: } & \text { Facioscapulohumeral muscular dystrophy } \\ \text { OPMD: } & \text { Oculopharyngeal muscular dystrophy } \\ \text { MD: } & \text { Myotonic dystrophy } \\ \text { MDPK: } & \text { Protein kinase gene } \\ \text { LH: } & \text { Luteinizing hormone } \\ \text { FFMI: } & \text { Fat-free mass index } \\ \text { FMI: } & \text { Higher fat mass index } \\ \text { IR-A: } & \text { Isoform A-Insulin receptor } \\ \text { IR-B: } & \text { Isoform B-Insulin receptor. }\end{array}$

\section{Acknowledgments}

This paper was carried out as part of the research Insulin resistance and obesity in Duchenne/Becker muscular dystrophy, supported by the Coordinación de Investigación Médica en Salud, IMSS, México (Grant no. FIS/IMSS/PROT/076), Instituto de Ciencia y Tecnología del Distrito Federal México, D. F. México and Association Francaise contre les Myophaties. The authors acknowledge Sharon Morey, Scientific Communications, for providing editorial assistance.

\section{References}

[1] I. Dalkilic and L. M. Kunkel, "Muscular dystrophies: genes to pathogenesis," Current Opinion in Genetics and Development, vol. 13, no. 3, pp. 231-238, 2003.

[2] T. A. Rando, "The dystrophin-glycoprotein complex, cellular signaling, and the regulation of cell survival in the muscular dystrophies," Muscle and Nerve, vol. 24, no. 12, pp. 15751594, 2001.

[3] K. Bushby, "Recent advances in paediatric muscular dystrophies," Current Paediatrics, vol. 14, no. 3, pp. 214-222, 2004.

[4] B. Motlagh, J. R. MacDonald, and M. A. Tarnopolsky, "Nutritional inadequacy in adults with muscular dystrophy," Muscle and Nerve, vol. 31, no. 6, pp. 713-718, 2005.

[5] M. L. Bianchi, D. Biggar, K. Bushby, A. D. Rogol, M. M. Rutter, and B. Tseng, "Endocrine aspects of duchenne muscular dystrophy," Neuromuscular Disorders, vol. 21, no. 4, pp. 298-303, 2011.

[6] A. G. Smith and G. E. O. Muscat, "Skeletal muscle and nuclear hormone receptors: implications for cardiovascular and metabolic disease," International Journal of Biochemistry and Cell Biology, vol. 37, no. 10, pp. 2047-2063, 2005.

[7] M. A. Abdul-Ghani and R. A. Defronzo, "Pathogenesis of insulin resistance in skeletal muscle," Journal of Biomedicine and Biotechnology, vol. 2010, Article ID 476279, 2010.

[8] M. Watanabe, H. Hayasaki, T. Tamayama, and M. Shimada, "Histologic distribution of insulin and glucagon receptors," Brazilian Journal of Medical and Biological Research, vol. 31, no. 2, pp. 243-256, 1998.
[9] A. M. Borissova, T. I. Tankova, and D. J. Koev, "Insulin secretion, peripheral insulin sensitivity and insulin-receptor binding in subjects with different degrees of obesity," Diabetes and Metabolism, vol. 30, no. 5, pp. 425-431, 2004.

[10] A. Aartsma-Rus, J. C. T. Van Deutekom, I. F. Fokkema, G. J. B. Van Ommen, and J. T. Den Dunnen, "Entries in the Leiden Duchenne muscular dystrophy mutation database: an overview of mutation types and paradoxical cases that confirm the reading-frame rule," Muscle and Nerve, vol. 34, no. 2, pp. 135-144, 2006.

[11] K. Bushby, R. Finkel, D. J. Birnkrant et al., "Diagnosis and management of Duchenne muscular dystrophy, part 1: diagnosis, and pharmacological and psychosocial management," The Lancet Neurology, vol. 9, no. 1, pp. 77-93, 2010.

[12] K. Bushby, J. Bourke, R. Bullock, M. Eagle, M. Gibson, and J. Quinby, "The multidisciplinary management of Duchenne muscular dystrophy," Current Paediatrics, vol. 15, no. 4, pp. 292-300, 2005.

[13] J. Gonzalez-Bermejo, F. Lofaso, L. Falaize et al., "Resting energy expenditure in Duchenne patients using home mechanical ventilation," European Respiratory Journal, vol. 25, no. 4, pp. 682-687, 2005.

[14] J. Finsterer and C. Stöllberger, "The heart in human dystrophinopathies," Cardiology, vol. 99, no. 1, pp. 1-19, 2003.

[15] M. Eagle, S. V. Baudouin, C. Chandler, D. R. Giddings, R. Bullock, and K. Bushby, "Survival in Duchenne muscular dystrophy: improvements in life expectancy since 1967 and the impact of home nocturnal ventilation," Neuromuscular Disorders, vol. 12, no. 10, pp. 926-929, 2002.

[16] M. Koening, A. H. Beggs, M. Moyer et al., "The molecular basis for Duchenne versus becker muscular dystrophy: correlation of severity with type of deletion," American Journal of Human Genetics, vol. 45, no. 4, pp. 498-506, 1989.

[17] K. M. D. Bushby and D. Gardner-Medwin, "The clinical, genetic and dystrophin characteristics of Becker muscular dystrophy," Journal of Neurology, vol. 240, pp. 98-104, 1993.

[18] G. Nigro, L. I. Comi, L. Politano, and R. J. I. Bain, "The incidence and evolution of cardiomyopathy in Duchenne muscular dystrophy," International Journal of Cardiology, vol. 26, no. 3, pp. 271-277, 1990.

[19] A. H. Beggs, E. P. Hoffman, J. R. Snyder et al., "Exploring the molecular basis for variability among patients with Becker muscular dystrophy: dystrophin gene and protein studies," American Journal of Human Genetics, vol. 49, no. 1, pp. 5467, 1991.

[20] G. Nigro, L. I. Comi, L. Politano, and R. J. I. Bain, "The incidence and evolution of cardiomyopathy in Duchenne muscular dystrophy," International Journal of Cardiology, vol. 26, no. 3, pp. 271-277, 1990.

[21] A. E. H. Emery, "X-linked muscular dystrophy with early contractures and cardiomyopathy (Emery-Dreifuss type)," Clinical Genetics, vol. 32, no. 5, pp. 360-367, 1987.

[22] A. Muchir and H. J. Worman, "Emery-Dreifuss muscular dystrophy," Current Neurology and Neuroscience Reports, vol. 7, no. 1, pp. 78-83, 2007.

[23] L. P. Rowland, M. Fetell, and M. Olarte, "Emery-Dreifuss muscular dystrophy," Annals of Neurology, vol. 5, no. 2, pp. 111-117, 1979.

[24] H. M. Becane, G. Bonne, S. Varnous et al., "High incidence of sudden death with conduction system and myocardial disease due to lamins A and C gene mutation," Pacing and Clinical Electrophysiology, vol. 23, no. 11 I, pp. 1661-1666, 2000 . 
[25] K. E. Davies and K. J. Nowak, "Molecular mechanisms of muscular dystrophies: old and new players," Nature Reviews Molecular Cell Biology, vol. 7, no. 10, pp. 762-773, 2006.

[26] B. S. Emanuel, E. H. Zackai, and S. H. Tucker, "Further evidence for Xp21 location of Duchenne muscular dystrophy (DMD) locus: X;9 translocation in a female with DMD," Journal of Medical Genetics, vol. 20, no. 6, pp. 461-463, 1983.

[27] G. T. Carter, M. D. Weiss, J. R. Chamberlain et al., "Aging with muscular dystrophy: pathophysiology and clinical management," Physical Medicine and Rehabilitation Clinics of North America, vol. 21, no. 2, pp. 429-450, 2010.

[28] J. M. Ervasti, K. Ohlendieck, S. D. Kahl, M. G. Gaver, and K. P. Campbell, "Deficiency of a glycoprotein component of the dystrophin complex in dystrophic muscle," Nature, vol. 345, no. 6273, pp. 315-319, 1990.

[29] M. Yoshida and E. Ozawa, "Glycoprotein complex anchoring dystrophin to sarcolemma," The Journal of Biochemistry, vol. 108, no. 5, pp. 748-752, 1990.

[30] E. R. Barton, "Impact of sarcoglycan complex on mechanical signal transduction in murine skeletal muscle," American Journal of Physiology, vol. 290, no. 2, pp. C411-C419, 2006.

[31] E. Bonilla, C. E. Samitt, A. F. Miranda et al., "Duchenne muscular dystrophy: deficiency of dystrophin at the muscle cell suface," Cell, vol. 54, no. 4, pp. 447-452, 1988.

[32] Z. Ren, C. Zhou, Y. Xu, J. Deng, H. Zeng, and Y. Zeng, "Mutation and haplotype analysis for Duchenne muscular dystrophy by single cell multiple displacement amplification," Molecular Human Reproduction, vol. 13, no. 6, pp. 431436, 2007.

[33] D. J. Blake, A. Weir, S. E. Newey, and K. E. Davies, "Function and genetics of dystrophin and dystrophin-related proteins in muscle," Physiological Reviews, vol. 82, no. 2, pp. 291-329, 2002.

[34] G. Bonne, M. R. Di Barletta, S. Varnous et al., "Mutations in the gene encoding lamin $\mathrm{A} / \mathrm{C}$ cause autosomal dominant Emery-Dreifuss muscular dystrophy," Nature Genetics, vol. 21, no. 3, pp. 285-288, 1999.

[35] S. Bione, E. Maestrini, S. Rivella et al., "Identification of a novel X-linked gene responsible for Emery-Dreifuss muscular dystrophy," Nature Genetics, vol. 8, no. 4, pp. 323-327, 1994.

[36] H. J. Worman and G. Bonne, "Laminopathies': a wide spectrum of human diseases," Experimental Cell Research, vol. 313, no. 10, pp. 2121-2133, 2007.

[37] K. L. Wydner, J. A. McNeil, F. Lin, H. J. Worman, and J. B. Lawrence, "Chromosomal assignment of human nuclear envelope protein genes LMNA, LMNB1, and LBR by fluorescence in situ hybridization," Genomics, vol. 32, no. 3, pp. 474-478, 1996.

[38] U. Aebi, J. Cohn, L. Buhle, and L. Gerace, "The nuclear lamina is a meshwork of intermediate-type filaments," Nature, vol. 323 , no. 6088 , pp. 560-564, 1986.

[39] J. G. Tidball and M. Wehling-Henricks, "Damage and inflammation in muscular dystrophy: potential implications and relationships with autoimmune myositis," Current Opinion in Rheumatology, vol. 17, no. 6, pp. 707-713, 2005.

[40] T. M. Al-Harbi, L. J. Bainbridge, M. J. McQueen, and M. A. Tarnopolsky, "Hypogonadism is common in men with myopathies," Journal of Clinical Neuromuscular Disease, vol. 9, no. 4, pp. 397-401, 2008.

[41] B. H. P. Nagel, W. Mortier, M. Elmlinger, H. A. Wollmann, K. Schmitt, and M. B. Ranke, "Short stature in Duchenne muscular dystrophy: a study of 34 patients," Acta Paediatrica, vol. 88, no. 1, pp. 62-65, 1999.
[42] A. C. Söderpalm, P. Magnusson, A. C. Åhlander et al., "Low bone mineral density and decreased bone turnover in Duchenne muscular dystrophy," Neuromuscular Disorders, vol. 17, no. 11-12, pp. 919-928, 2007.

[43] R. Sih, J. E. Morley, F. E. Kaiser, H. M. Perry, P. Patrick, and C. Ross, "Testosterone replacement in older hypogonadal men: a 12-month randomized controlled trial," Journal of Clinical Endocrinology and Metabolism, vol. 82, no. 6, pp. 1661-1667, 1997.

[44] S. T. Page, J. K. Amory, F. D. Bowman et al., "Exogenous testosterone $(\mathrm{T})$ alone or with finasteride increases physical performance, grip strength, and lean body mass in older men with low serum T," Journal of Clinical Endocrinology and Metabolism, vol. 90, no. 3, pp. 1502-1510, 2005.

[45] L. Merlini, C. Granata, A. Ballestrazzi et al., "Growth hormone evaluation in duchenne muscular dystrophy," The Italian Journal of Neurological Sciences, vol. 9, no. 5, pp. 471475, 1988.

[46] G. R. Frank and R. E. Smith, "Effective growth hormone therapy in a growth hormone deficient patient with Duchenne muscular dystropy without evidence of acceleration of the dystrophic process," Journal of Pediatric Endocrinology and Metabolism, vol. 14, no. 2, pp. 211-214, 2001.

[47] D. G. Leung, E. L. Germain-Lee, B. E. Denger, and K. R. Wagner, "Report on the second endocrine aspects of duchenne muscular dystrophy conference December 1-2, 2010, Baltimore, Maryland, USA," Neuromuscular Disorders, vol. 21, no. 8, pp. 594-601, 2011.

[48] D. E. McNeil, C. Davis, D. Jillapalli, S. Targum, A. Durmowicz, and T. R. Coté, "Duchenne muscular dystrophy: drug development and regulatory considerations," Muscle and Nerve, vol. 41, no. 6, pp. 740-745, 2010.

[49] J. V. Chakkalakal, J. Thompson, R. J. Parks, and B. J. Jasmin, "Molecular, cellular, and pharmacological therapies for Duchenne/Becker muscular dystrophies," FASEB Journal, vol. 19, no. 8, pp. 880-891, 2005.

[50] G. Q. Zhou, H. Q. Xie, S. Z. Zhang, and Z. M. Yang, "Current understanding of dystrophin-related muscular dystrophy and therapeutic challenges ahead," Chinese Medical Journal, vol. 119, no. 16, pp. 1381-1391, 2006.

[51] H. G. Radley, A. De Luca, G. S. Lynch, and M. D. Grounds, "Duchenne muscular dystrophy: focus on pharmaceutical and nutritional interventions," International Journal of Biochemistry and Cell Biology, vol. 39, no. 3, pp. 469-477, 2007.

[52] M. Zatz, R. T. B. Betti, J. M. Opitz, and J. F. Reynolds, "Benign Duchenne muscular dystrophy in a patient with growth hormone deficiency: a five years follow-up," American Journal of Medical Genetics, vol. 10, no. 3, pp. 301-304, 1981.

[53] R. D. Griffiths and R. H. T. Edwards, "A new chart for weight control in Duchenne muscular dystrophy," Archives of Disease in Childhood, vol. 63, no. 10, pp. 1256-1258, 1988.

[54] T. N. Willig, L. Carlier, M. Legrand, H. Riviere, and J. Navarro, "Nutritional assessment in Duchenne muscular dystrophy," Developmental Medicine and Child Neurology, vol. 35, no. 12, pp. 1074-1082, 1993.

[55] M. Zanardi, A. Tagliabue, S. Orcesi, A. Berardinelli, C. Uggetti, and A. Pichiecchio, "Body composition with dual energy x-ray absorptiometry in Duchenne muscular dystrophy: correlation of lean body mass with muscle function," Muscle Nerve, vol. 19, no. 6, pp. 777-779, 2003.

[56] L. Martigne, J. Salleron, M. Mayer et al., "Natural evolution of weight status in Duchenne muscular dystrophy: a retrospective audit," British Journal of Nutrition, vol. 105, no. 10, pp. 1486-1491, 2011. 
[57] Z. E. Davidson and H. Truby, "A review of nutrition in Duchenne muscular dystrophy," Journal of Human Nutrition and Dietetics, vol. 22, no. 5, pp. 383-393, 2009.

[58] R. R. Wolfe, "Control of muscle protein breakdown: effects of activity and nutritional states," International Journal of Sport Nutrition, vol. 11, pp. S164-S169, 2001.

[59] O. Borrelli, G. Salvia, V. Mancini et al., "Evolution of gastric electrical features and gastric emptying in children with Duchenne and Becker muscular dystrophy," American Journal of Gastroenterology, vol. 100, no. 3, pp. 695-702, 2005.

[60] M. Shimizu-Fujiwara, H. Komaki, E. Nakagawa et al., "Decreased resting energy expenditure in patients with Duchenne muscular dystrophy," Brain and Development, vol. 34, no. 3, pp. 206-212, 2012.

[61] M. R. Güell, M. Avendano, J. Fraser, and R. Goldstein, "Pulmonary and nonpulmonary alterations in Duchenne muscular dystrophy," Archivos de Bronconeumologia, vol. 43, no. 10, pp. 557-561, 2007.

[62] M. Pane, I. Vasta, S. Messina et al., "Feeding problems and weight gain in Duchenne muscular dystrophy," European Journal of Paediatric Neurology, vol. 10, no. 5-6, pp. 231-236, 2006.

[63] S. E. Barlow and W. H. Dietz, "Obesity evaluation and treatment: expert Committee recommendations. The Maternal and Child Health Bureau, Health Resources and Services Administration and the Department of Health and Human Services," Pediatrics, vol. 102, no. 3, p. E29, 1998.

[64] F. Lopez-Jimenez and W. R. Miranda, "Diagnosing obesity: beyond BMI," American Medical Association Journal of Ethics, vol. 12, no. 4, pp. 292-298, 2010.

[65] E. Mok, G. Letellier, J. M. Cuisset, A. Denjean, F. Gottrand, and R. Hankard, "Assessing change in body composition in children with Duchenne muscular dystrophy: anthropometry and bioelectrical impedance analysis versus dual-energy X-ray absorptiometry," Clinical Nutrition, vol. 29, no. 5, pp. 633-638, 2010.

[66] F. Kanda, Y. Fujii, K. Takahashi, and T. Fujita, "Dual-energy $\mathrm{X}$-ray absorptiometry in neuromuscular diseases," Muscle and Nerve, vol. 17, no. 4, pp. 431-435, 1994.

[67] E. Mok, L. Béghin, P. Gachon et al., "Estimating body composition in children with Duchenne muscular dystrophy: comparison of bioelectrical impedance analysis and skinfoldthickness measurement," American Journal of Clinical Nutrition, vol. 83, no. 1, pp. 65-69, 2006.

[68] J. Drefus, G. Schapira, F. Schapira, and J. Demos, "Activites enzymatiques du muscle humain: recherches sur la bichimie comparee de l'homme normal et myopathique et du rat," Clinica Chimica Acta, vol. 1, no. 5, pp. 434-449, 1956.

[69] D. A. Ellis, "Intermediary metabolism of muscle in Duchenne muscular dystrophy," British Medical Bulletin, vol. 36, no. 2, pp. 165-171, 1980.

[70] U. Sharma, S. Atri, M. C. Sharma, C. Sarkar, and N. R. Jagannathan, "Skeletal muscle metabolism in Duchenne muscular dystrophy (DMD): an in-vitro proton NMR spectroscopy study," Magnetic Resonance Imaging, vol. 21, no. 2, pp. 145153, 2003.

[71] A. Ibrahimi, A. Bonen, W. D. Blinn et al., "Muscle-specific overexpression of FAT/CD36 enhances fatty acid oxidation by contracting muscle, reduces plasma triglycerides and fatty acids, and increases plasma glucose and insulin," Journal of Biological Chemistry, vol. 274, no. 38, pp. 26761-26766, 1999.

[72] H. Nishio, H. Wada, T. Matsuo et al., "Glucose, free fatty acid and ketone body metabolism in Duchenne muscular dystrophy," Brain and Development, vol. 12, no. 4, pp. 390402, 1990.

[73] G. R. Freidenberg and J. M. Olefsky, "Dissociation of insulin resistance and decreased insulin receptor binding in Duchenne muscular dystrophy," Journal of Clinical Endocrinology and Metabolism, vol. 60, no. 2, pp. 320-327, 1985.

[74] R. DeFronzo, D. Deibert, and R. Hendler, "Insulin sensitivity and insulin binding to monocytes in maturity-onset diabetes," Journal of Clinical Investigation, vol. 63, no. 5, pp. 939-946, 1979.

[75] B. Mokri and A. G. Engel, "Duchenne dystrophy: electron microscopic findings pointing to a basic or early abnormality in the plasma membrane of the muscle fiber," Neurology, vol. 25, no. 12, pp. 1111-1120, 1975.

[76] E. Yechiel and Y. Barenholz, "Relationships between membrane lipid composition and biological properties of rat myocytes," Journal of Biological Chemistry, vol. 260, no. 16, pp. 9123-9131, 1985.

[77] T. J. Hsieh, C. K. Wang, H. Y. Chuang, Y. J. Jong, C. W. Li, and G. C. Liu, "In Vivo proton magnetic resonance spectroscopy assessment for muscle metabolism in neuromuscular diseases," Journal of Pediatrics, vol. 151, no. 3, pp. 319-321, 2007.

[78] I. Illa, C. Serrano, E. Gallardo et al., "Distal anterior compartment myopathy: a dysferlin mutation causing a new muscular dystrophy phenotype," Annals of Neurology, vol. 49, pp. 130-134, 2001.

[79] L. Broglio, M. Tentorio, M. S. Cotelli et al., "Limb-girdle muscular dystrophy-associated protein diseases," Neurologist, vol. 16, no. 6, pp. 340-352, 2010.

[80] A. A. Amato and R. J. Barohn, "Inclusion body myositis: old and new concepts," Journal of Neurology, Neurosurgery and Psychiatry, vol. 80, no. 11, pp. 1186-1193, 2009.

[81] P. Reilich, N. Schramm, B. Schoser et al., "Facioscapulohumeral muscular dystrophy presenting with unusual phenotypes and atypical morphological features of vacuolar myopathy," Journal of Neurology, vol. 257, no. 7, pp. 1108$1118,2010$.

[82] B. Brais, "Oculopharyngeal muscular dystrophy: a polyalanine myopathy," Current Neurology and Neuroscience Reports, vol. 9, no. 1, pp. 76-82, 2009.

[83] P. Reilich, N. Schramm, B. Schoser et al., "Facioscapulohumeral muscular dystrophy presenting with unusual phenotypes and atypical morphological features of vacuolar myopathy," Journal of Neurology, vol. 257, no. 7, pp. 11081118, 2010.

[84] D. H. Cho and S. J. Tapscott, "Myotonic dystrophy: emerging mechanisms for DM1 and DM2," Biochimica et Biophysica Acta, vol. 1772, no. 2, pp. 195-204, 2007.

[85] P. S. H. Harper, Myotonic Dystrophy, W.B. Saunders, London, UK, 3rd edition, 2001.

[86] J. D. Brook, M. E. McCurrach, H. G. Harley et al., "Molecular basis of myotonic dystrophy: expansion of a trinucleotide (CTG) repeat at the 3' end of a transcript encoding a protein kinase family member," Cell, vol. 68, no. 4, pp. 799-808, 1992.

[87] C. E. M. De Die-Smulders, C. J. Höweler, C. Thijs et al., "Age and causes of death in adult-onset myotonic dystrophy," Brain, vol. 121, no. 8, pp. 1557-1563, 1998.

[88] G. Sicot, F. Gourdon, and M. Gomes, "Myotonic dystrophy, when simple repeats reveal complex pathogenic entities: new findings and future challenges," Human Molecular Genetics, vol. 20, no. 2, pp. 116-123, 2011.

[89] M. A. Hauser, S. K. Horrigan, P. Salmikangas et al., "Myotilin is mutated in limb girdle muscular dystrophy 1A," Human Molecular Genetics, vol. 9, no. 14, pp. 2141-2147, 2000. 
[90] C. T. Rocha and E. P. Hoffman, "Limb-girdle and congenital muscular dystrophies: current diagnostics, management, and emerging technologies," Current Neurology and Neuroscience Reports, vol. 10, no. 4, pp. 267-276, 2010.

[91] G. Antonini, A. Clemenzi, E. Bucci et al., "Hypogonadism in DM1 and its relationship to erectile dysfunction," Journal of Neurology, vol. 258, no. 7, pp. 1247-1253, 2011.

[92] J. A. Vazquez, J. A. Pinies, P. Martul, A. De los Rios, S. Gatzambide, and M. A. Busturia, "Hypothalamic-pituitarytesticular function in 70 patients with myotonin dystrophy," Journal of Endocrinological Investigation, vol. 13, no. 5, pp. 375-379, 1990.

[93] J. M. Gomez Saez, J. M. Fernandez Real, M. Fernandez Castaner, M. A. Navarro Moreno, J. A. Martinez Matos, and J. Soler Ramon, "Study on growth hormone and insulin secretion in myotonic dystrophy," Clinical Investigator, vol. 72, no. 7, pp. 508-511, 1994.

[94] I. Mastrogiacomo, G. Bonanni, E. Menegazzo et al., "Clinical and hormonal aspects of male hypogonadism in myotonic dystrophy," Italian Journal of Neurological Sciences, vol. 17, no. 1, pp. 59-65, 1996.

[95] M. Mahadevan, C. Tsilfidis, L. Sabourin et al., "Myotonic dystrophy mutation: an unstable CTG repeat in the 3' untranslated region of the gene," Science, vol. 255, no. 5049, pp. 1253-1255, 1992.

[96] J. A. Vazquez, J. A. Pinies, P. Martul, A. De los Rios, S. Gatzambide, and M. A. Busturia, "Hypothalamic-pituitarytesticular function in 70 patients with myotonin dystrophy," Journal of Endocrinological Investigation, vol. 13, no. 5, pp. 375-379, 1990.

[97] I. Mastrogiacomo, G. Bonanni, E. Menegazzo et al., "Clinical and hormonal aspects of male hypogonadism in myotonic dystrophy," Italian Journal of Neurological Sciences, vol. 17, no. 1, pp. 59-65, 1996.

[98] R. C. Griggs, D. Halliday, W. Kingston, and R. T. Moxley, "Effect of testosterone on muscle protein synthesis in myotonic dystrophy," Annals of Neurology, vol. 20, no. 5, pp. 590-596, 1986.

[99] G. Antonini, A. Clemenzi, E. Bucci et al., "Hypogonadism in DM1 and its relationship to erectile dysfunction," Journal of Neurology, vol. 258, no. 7, pp. 1247-1253, 2011.

[100] V. Chaudhry, T. Umapathi, and W. J. Ravich, "Neuromuscular diseases and disorders of the alimentary system," Muscle and Nerve, vol. 25, no. 6, pp. 768-784, 2002.

[101] T. Matsumura, H. Iwahashi, T. Funahashi et al., "A crosssectional study for glucose intolerance of myotonic dystrophy," Journal of the Neurological Sciences, vol. 276, no. 1-2, pp. 60-65, 2009.

[102] P. Kaminsky, M. Poussel, L. Pruna, J. Deibener, B. Chenuel, and B. Brembilla-Perrot, "Organ dysfunction and muscular disability in myotonic dystrophy type 1," Medicine, vol. 90, no. 4 , pp. 262-268, 2011.

[103] S. Aitkens, D. D. Kilmer, N. C. Wright, and M. A. McCrory, "Metabolic syndrome in neuromuscular disease," Archives of Physical Medicine and Rehabilitation, vol. 86, no. 5, pp. 10301036, 2005.

[104] P. Björntorp and R. Rosmond, "The metabolic syndromea neuroendocrine disorder?" British Journal of Nutrition, vol. 83, no. 1, pp. S49-S57, 2000.

[105] R. S. Savkur, A. V. Philips, and T. A. Cooper, "Aberrant regulation of insulin receptor alternative splicing is associated with insulin resistance in myotonic dystrophy," Nature Genetics, vol. 29, no. 1, pp. 40-47, 2001.
[106] D. E. Moller, A. Yokota, J. F. Caro, and J. S. Flier, "Tissuespecific expression of two alternatively spliced insulin receptor mRNAs in man," Molecular Endocrinology, vol. 3, no. 8, pp. 1263-1269, 1989.

[107] J. C. Walsh, J. R. Turtle, S. Miller, and J. G. Mcleod, "Abnormalities of insulin secretion in dystrophia myotonica," Brain, vol. 93, no. 4, pp. 731-742, 1970.

[108] G. Perseghin, A. Caumo, C. Arcelloni et al., "Contribution of abnormal insulin secretion and insulin resistance to the pathogenesis of type 2 diabetes in myotonic dystrophy," Diabetes Care, vol. 26, no. 7, pp. 2112-2118, 2003.

[109] F. Bertuzzi, A. M. Davalli, R. Nano et al., "Mechanisms of coordination of $\mathrm{Ca} 2+$ signals in pancreatic islet cells," Diabetes, vol. 48, no. 10, pp. 1971-1978, 1999. 


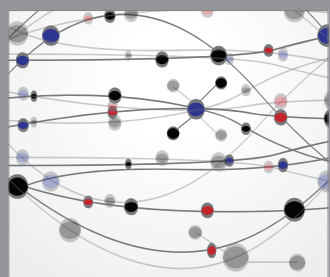

The Scientific World Journal
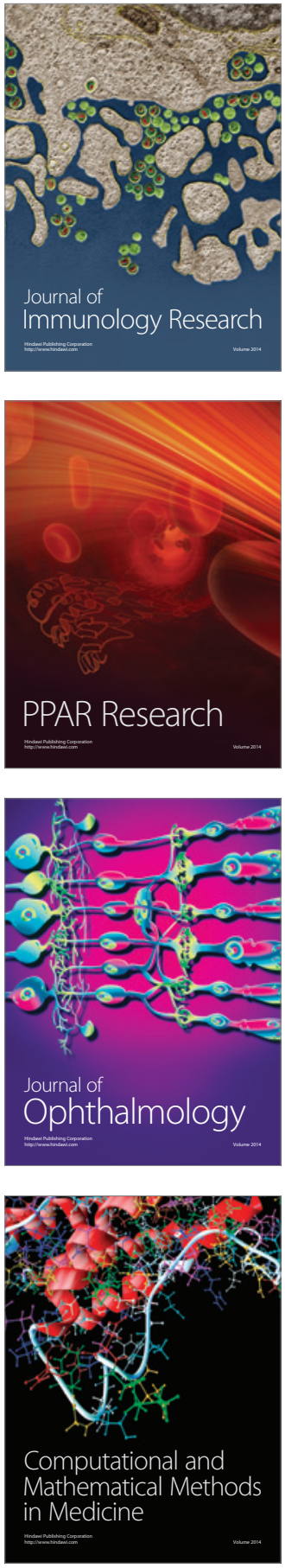

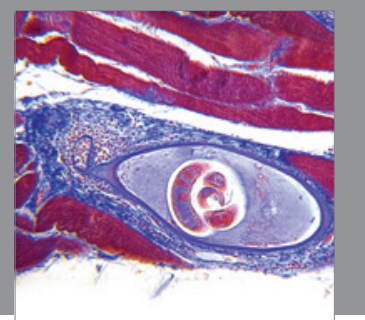

Gastroenterology

Research and Practice
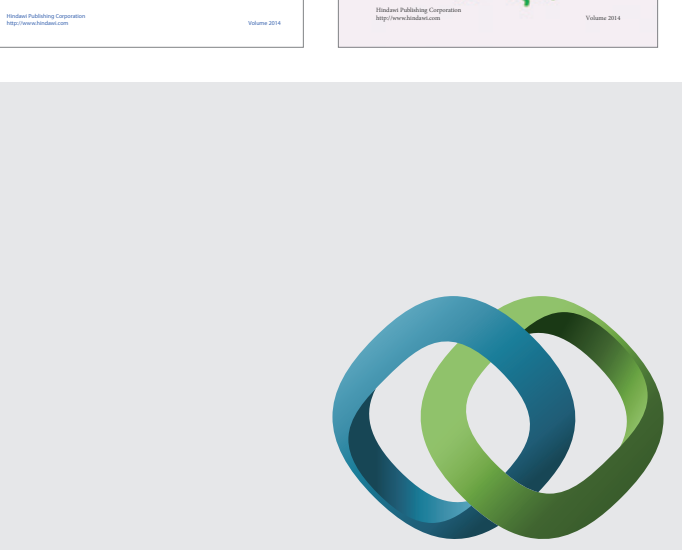

\section{Hindawi}

Submit your manuscripts at

http://www.hindawi.com
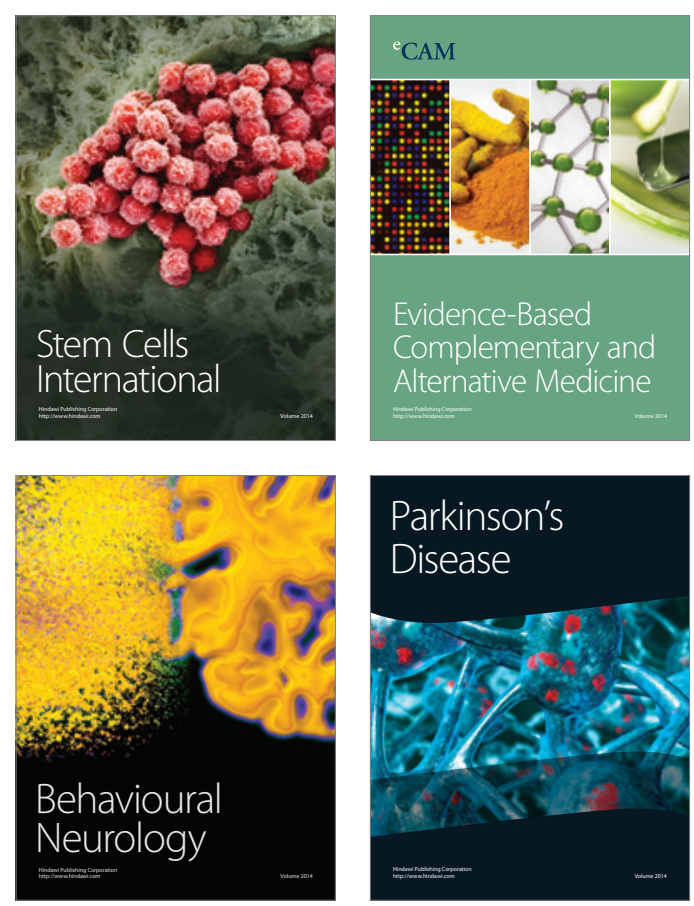

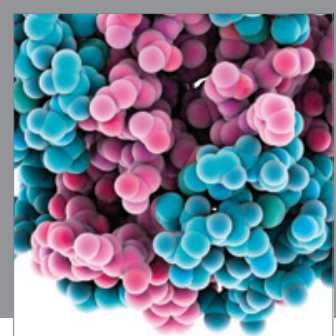

Journal of
Diabetes Research

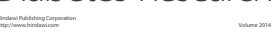

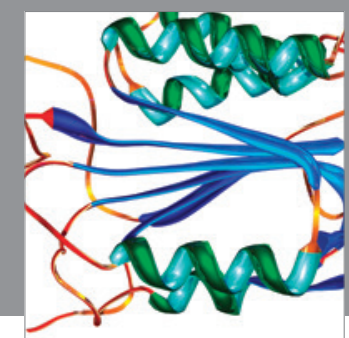

Disease Markers
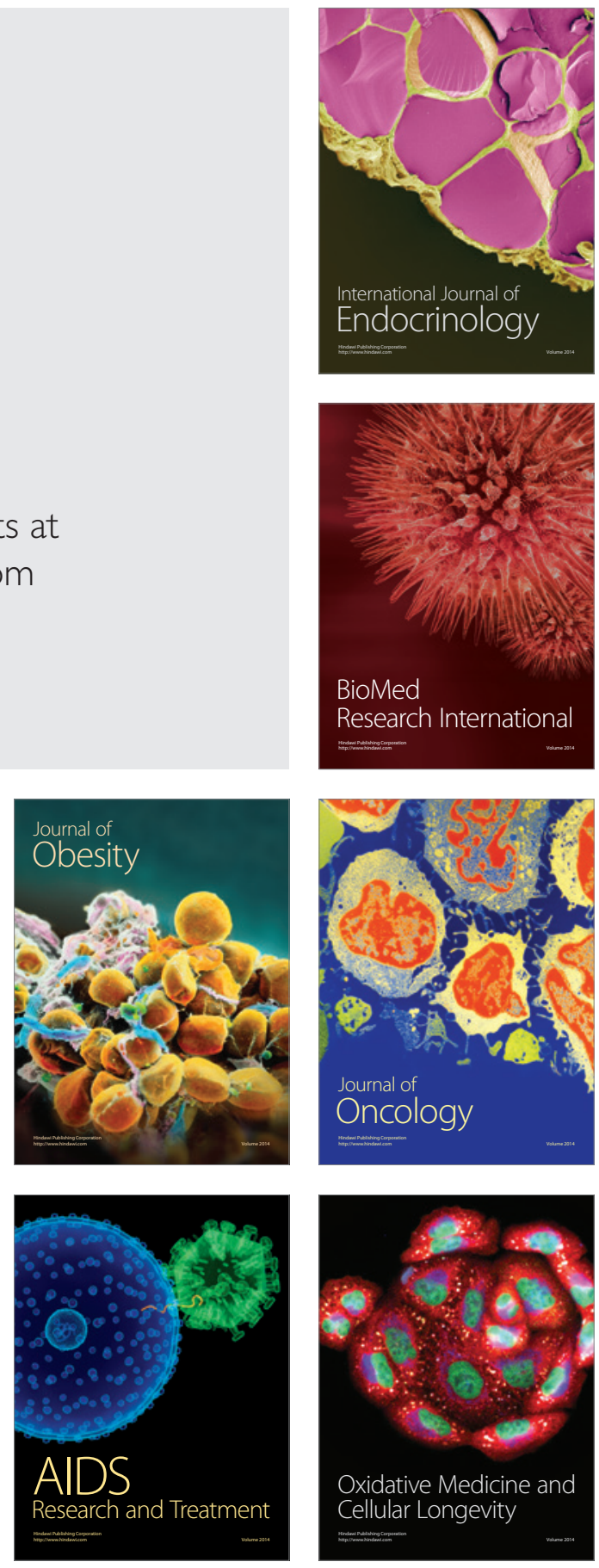